\title{
Collusion in quality-segmented markets
}

\author{
Iwan Bos $^{1}$ | Marco A. Marini ${ }^{2}$
}

\begin{abstract}
${ }^{1}$ Department of Organisation, Strategy and Entrepreneurship, Maastricht University, Maastricht, The Netherlands

${ }^{2}$ Department of Social and Economic

Sciences, University of Rome La

Sapienza and CREI, Rome, Italy

\section{Correspondence}

Marco A. Marini, Department of Social and Economic Sciences, University of Rome La Sapienza and CREI, Piazzale Aldo Moro, 5, 00185 Rome, Italy.

Email: marco.marini@uniroma1.it
\end{abstract}

\section{Funding information}

Sapienza Università di Roma

\begin{abstract}
This paper analyzes price collusion in a repeated game with two submarkets: a standard and a premium quality segment. Within this setting, we study four types of price-fixing agreement: (i) a segment-wide cartel in the premium submarket only, (ii) a segmentwide cartel in the standard submarket only, (iii) two segment-wide cartels, and (iv) an industry-wide cartel. We present a complete characterization of the collusive pricing equilibrium and examine the corresponding effect on market shares and welfare. Partial cartels operating in a sufficiently large segment lose market share and the industry-wide cartel prefers to maintain market shares at precollusive levels. The impact on consumer and social welfare critically depends on the cost of producing quality. Moreover, given that there is a cartel, more collusion can be beneficial for society as a whole.
\end{abstract}

\section{1 | INTRODUCTION}

Virtually all markets can be segmented by product variety or customer group. In principle there are many segmentation dimensions, but perhaps the most common one is (perceived) quality. Quality submarkets emerge due to factors on both the demand and the supply side. On the demand side, differences exist in the ability and willingness to pay for product quality. On the supply side, there are typically larger costs associated with the production of higher-quality goods and services. The presence of such quality segments has a nontrivial effect on firms' strategies and on pricing in particular. 
The purpose of this paper is to examine price collusion in quality-segmented markets. We do so by studying a price-setting supergame with two quality submarkets: a standard and a premium segment. It is assumed that products within each segment are perfect substitutes and that they are differentiated across segments. In the spirit of Mussa and Rosen (1978), Gabszewicz and Thisse (1979), and Shaked and Sutton (1982), consumers have heterogeneous valuations for quality and buy from the firm with the best value proposition. The model thus effectively consists of two classical homogeneous-good Bertrand games that are connected through a vertical dimension. Within this framework, we consider four types of price-fixing agreement: (i) a segment-wide cartel in the premium submarket only, (ii) a segment-wide cartel in the standard submarket only, (iii) two segment-wide cartels, one in each submarket, and (iv) an industry-wide cartel.

It is worth noting that these scenarios have been observed in (antitrust) practice. For example, a recent German coffee roaster cartel consisted exclusively of premium brands and faced competition from lower-quality private labels (e.g., store brands of Aldi and Lidl). ${ }^{1}$ During the interwar period, an incomplete Swiss dyestuff export cartel competed with inferior quality rivals from other countries. ${ }^{2}$ By contrast, a French yogurt cartel fixed prices of supermarket own-brand yogurt, but premium producers like Danone did not participate in the collusive agreement. $^{3}$ As yet another example, a German sausage cartel spanned a large part of the market and included both private label and premium brands. ${ }^{4}$

With this in mind, we employ our model to address questions such as: What does optimal segment-wide collusion look like? How does price-fixing affect the market share of the qualitysegments? What are the welfare implications of the different types of price conspiracies? Is a cartel in a premium segment more or less detrimental to consumers and society at large than a cartel in a standard quality segment?

Our analysis begins by providing a complete characterization of the collusive price equilibrium for all four scenarios. If collusion is sustainable, then a segment-wide cartel can sustain the joint profit-maximizing price. The reason is that a partial cartel effectively operates as a monopolist within its submarket, which faces competition only from the adjacent segment. For any collusive price between marginal cost and the joint profit maximum, it is therefore optimal for a cheating firm to set its price slightly below the cartel price. This implies that deviating profits are proportionate to collusive profits so that the critical discount factor is independent of the level of the cartel price. Hence, when firms within a segment can sustain a supracompetitive price, they can sustain the joint profit maximum. By contrast, the industry-wide cartel charges monopoly prices only when its members are sufficiently patient.

Cartel prices are increasing with the inclusiveness of the coalition. That is, prices are higher when collusion spans the whole market and the industry-wide cartel sets (weakly) higher prices compared with when there are two segment-wide partial cartels. The latter is driven by the fact that the all-inclusive cartel internalizes the pricing externality across segments.

\footnotetext{
${ }^{1}$ See Hasnas and Wey (2015).

${ }^{2}$ See Schmitt and Weder (1998) for a detailed description of this cartel.

${ }^{3}$ See Bonnet and Bouamra-Mechemache (2019).

${ }^{4}$ See Hasnas and Wey (2015). The grocery examples are appealing because there typically is a clear difference between the (perceived) quality of the private label products and the premium brands. However, our analysis is not limited to such situations and effectively applies to any industry with distinct quality segments. Moreover, it also applies to cases of tacit collusion. For instance, even though there was no explicit cartel case, there is evidence of price collusion between two premium ice cream brands, Ben and Jerry's and Häagen-Dazs, for the year 2013. See Sullivan (2017).
} 
These collusive equilibria have an impact on the market share distribution. If there is a single segment-wide cartel, then there is a net movement of customers to the noncollusive segment. With two partial cartels, the change in segment size effectively depends on the competitive market share. If a segment is sufficiently small absent collusion, then cartel prices are set such that its sales share increases (and vice versa). The all-inclusive cartel prefers to maintain market shares at precollusive levels, which requires prices to rise more in the premium segment. It is noteworthy that such a market division rule has been frequently observed in antitrust practice. ${ }^{5}$ Also, we have assumed such an allocation scheme in Bos and Marini (2019), whereas here it emerges endogenously.

As to welfare, we delineate two distinct effects: a market size effect and a market share effect. The market size effect is the change in welfare that comes from buyers leaving the market. Part of the consumers in the standard segment derive little value from quality and they may no longer buy the product when its price increases. This market size effect is therefore absent when there is a partial cartel in the premium segment only since in that case the price of the standard quality product remains unaltered. In the other three scenarios, the price of the standard product rises so that the market size effect is strictly negative. The market share effect describes the movement of customers from one segment to the other. Since the value created is larger in the premium segment, this effect is positive when more consumers buy the highquality product. By contrast, it is negative when customers switch from the premium to the standard quality segment. These distinct effects, and in particular the fact that they might work in opposite directions, make the welfare impact of the different types of price conspiracy far from trivial.

We find that customer damages increase with the inclusiveness of the cartel, which is in line with expectations. Yet, whether a single partial cartel in the premium or in the standard submarket is more harmful depends on the relation between quality and costs. Specifically, a single cartel in the standard segment is more detrimental to buyers when unit costs rise sufficiently with quality. In that case, sellers in the standard segment have a relatively strong market position and this enables them to sustain a relatively high cartel price. This induces many buyers to leave the market, that is, there is a strong negative market size effect which significantly harms consumer welfare. In a similar vein, the impact on societal welfare depends on the degree to which costs increase with quality. Among others, we find that the (positive) market share effect may outweigh the (negative) market size effect. This has the implication that a single segment-wide cartel may be more detrimental to society than two segment-wide partial cartels. Therefore, given that there is collusion in one segment, a social planner might well prefer collusion over competition in the adjacent segment.

Full and partial collusion with quality differentiation has also recently been analyzed by Bos et al. (2020). The present paper differs in three important ways. First, whereas that work assumes each firm to produce a unique quality variant, our setting has one or more competitors offering the same quality. This horizontal dimension severely limits the market power of firms. Second, Bos et al. (2020) consider fully integrated cartels that operate as a single firm. One implication of this is that the cartel may decide to effectively give up on selling some quality variants by pricing them out of the market. In fact, this is shown to be profitable when costs do not rise too much with quality. Such a strategy is not feasible in our setting, however, because having no sales implies a violation of the incentive constraint. Indeed, a third difference with

${ }^{5}$ See, for example, Harrington (2006). 
Bos et al. (2020) is that they consider a static framework and therefore assume each cartel to set the joint profit-maximizing price. By contrast, since we analyze collusion in an infinitely repeated game setting, cartel contracts need to be incentive compatible.

There are a few other papers that use an infinitely repeated game framework to study collusion in markets with vertically differentiated products. ${ }^{6}$ Häckner (1994) and Symeonidis (1999), for instance, both analyze how the incentive to chisel on a collusive agreement depends on quality and reach opposite conclusions. In Bos and Marini (2019), we add to this by arguing that profit margins are a critical driver of deviating incentives. Ecchia and Lambertini (1997) explore the impact of a minimum quality standard and establish that such a standard can make it harder for firms to collude. A key difference with all this and related work is that firms are supposed to take a unique position along the quality spectrum, whereas here we consider quality segments in which two or more sellers offer the same quality. ${ }^{7}$

Another related strand of research considers heterogeneity in cartel size. For instance, Donsimoni (1985) examines a collusive price leadership model with differences in production costs. She shows the existence of a stable, less than all-inclusive cartel comprising the most efficient firms. Consistent with this result, Bos and Harrington (2010) find that the incentive to collude is positively related to firm size and that sufficiently small sellers may prefer not to take part in the anticompetitive coalition. More recently, De Roos and Smirnov (2020) study pricing strategies of a partial cartel assuming that consumers are imperfectly attentive. Among other things, they characterize the optimal collusive price path and show it may involve intertemporal price dispersion. Finally, Bos et al. (2020) establish that many different cartel sizes may emerge when products are vertically differentiated. None of these works considers partial collusion in quality-segmented markets, however.

This paper proceeds as follows. Section 2 introduces the model. In Section 3, we use this setting to study partial and full price collusion. Section 4 builds on this by presenting a welfare analysis. Section 5 concludes with a summary and suggestions for further work. All proofs are relegated to Appendix A.

\section{2 | MODEL}

Consider an industry with two quality segments: a low (standard) and a high (premium) quality segment. Let the set of low- and high-quality sellers be, respectively, given by $L=\{1, \ldots, l\}$ and $H=\{1, \ldots, h\}$, with $l, h \geq 2$. Each firm supplies a single quality variant of the product so that $l+h$ is the total number of firms. ${ }^{8}$ Within each segment, sellers are identical and their quality is indicated by $v_{i}$, where $i=l, h$ and $v_{h}>v_{l}>0$. Corresponding marginal costs of production are constant per unit of output and given by $c_{h}>c_{l} \geq 0$. It is therefore more expensive to manufacture the high-quality product. Interaction takes place for an infinite number of discrete periods and in each period $t \in \mathbb{N}$ producers simultaneously pick prices to maximize their

\footnotetext{
${ }^{6}$ For a detailed overview of this literature, see Marini (2018).

${ }^{7}$ Hasnas and Wey (2015) study partial and full collusion in a three-firm spatial setting. They effectively consider a high-quality segment in the sense that two horizontally differentiated premium producers are assumed to offer the same quality and face a lower-quality private label firm. In our model, each quality variant is supplied by two or more sellers and firms within a particular segment solely compete on price.

${ }^{8}$ We elaborate on the possibility of multiproduct firms in Appendix A.
} 
profits. The discount factor is $\delta \in(0,1)$ and all prices set up until $t-1$ are assumed common knowledge.

The demand side comprises consumers who are uniformly distributed over $[0,1]$ with a mass normalized to unity. The parameter $\theta$ describes the degree to which buyers value quality and a higher $\theta$ corresponds to a higher gross utility when consuming variant $v_{i} \cdot{ }^{9}$ Firms do not know a customer's valuation of quality. Consumers either purchase one unit of the product or choose an outside option for which the valuation is normalized to zero. Someone 'located' at $\theta$ therefore obtains the following utility:

$$
U(\theta)=\left\{\begin{aligned}
\theta v_{i}-p_{i} & \text { when buying quality } i, \\
0 & \text { when not buying },
\end{aligned}\right.
$$

where $p_{i} \in \mathbb{R}_{+}$is the price set by a firm offering quality $v_{i}, i=l, h$. Observe that this specification implicitly assumes firms within one segment to set the same price; a property that we verify below. To further economize on notation, we write $p_{l}$ and $p_{h}$ to indicate the prices set in the standard and premium segment, respectively. Finally, it is worth noting that some consumers prefer not to buy the product when prices are strictly positive in which case the market is not covered.

Let us now describe the demand for each firm. To begin, a consumer 'located' at $\theta_{0}$ is indifferent between buying from a firm $i \in L$ and the outside option when

$$
\theta_{0} v_{l}-p_{l}=0 \Rightarrow \theta_{0}=\frac{p_{l}}{v_{l}}
$$

In a similar vein, a consumer at $\theta_{1}$ is indifferent between buying from a firm $i \in L$ and a firm $i \in H$ when

$$
\theta_{1} v_{l}-p_{l}=\theta_{1} v_{h}-p_{h} \Rightarrow \theta_{1}=\frac{p_{h}-p_{l}}{v_{h}-v_{l}}
$$

Under the assumption that consumers spread evenly across equally priced firms, firm demand is then given by

$$
D_{l}\left(p_{l}, p_{h}\right)=\frac{\theta_{1}-\theta_{0}}{l}=\frac{v_{l} p_{h}-v_{h} p_{l}}{l\left(v_{h}-v_{l}\right) v_{l}}
$$

and

$$
D_{h}\left(p_{l}, p_{h}\right)=\frac{1-\theta_{1}}{h}=\frac{v_{h}-v_{l}-p_{h}+p_{l}}{h\left(v_{h}-v_{l}\right)}
$$

\footnotetext{
${ }^{9}$ An alternative interpretation is that consumers have the same valuation for quality, but differ in their incomes. See, e.g., Gabszewicz and Thisse (1979), Shaked and Sutton (1982) and, more recently, Klumpp and Su (2020).
} 
with concomitant profit functions:

$$
\pi_{l}\left(p_{l}, p_{h}\right)=\left(p_{l}-c_{l}\right) \cdot\left[\frac{v_{l} p_{h}-v_{h} p_{l}}{l\left(v_{h}-v_{l}\right) v_{l}}\right]
$$

and

$$
\pi_{h}\left(p_{l}, p_{h}\right)=\left(p_{h}-c_{h}\right) \cdot\left[\frac{v_{h}-v_{l}-p_{h}+p_{l}}{h\left(v_{h}-v_{l}\right)}\right] .
$$

In the ensuing analysis, we concentrate on situations in which each firm is active (i.e., has strictly positive sales). The following two assumptions provide sufficient conditions for an interior solution:

Assumption 1. $1>\frac{c_{h}-c_{l}}{v_{h}-v_{l}}>\frac{c_{l}}{v_{l}}$.

Assumption 2. Each firm chooses 'to be productive' over 'not to be productive' when both yield the same profit.

Roughly speaking, Assumption 1 ensures there is a market for both qualities in that it enables each firm to make a competitive value proposition. The first inequality creates scope for the high-quality segment by stating that the difference in product quality $\left(v_{h}-v_{l}\right)$ exceeds the extra costs of producing the premium good $\left(c_{h}-c_{l}\right)$. The second inequality holds when $v_{l} c_{h}>v_{h} c_{l}$ and, since $\theta_{1}>\theta_{0}$ requires $v_{l} p_{h}>v_{h} p_{l}$, this implies there is demand for the lowquality product when firms price at marginal cost. Assumption 2 states that firms have a weak preference for positive sales.

An implication of these two assumptions is that there is a unique static Nash equilibrium in which each seller sets price at marginal costs. Thus, none of them makes an economic profit absent collusion. Below, we indicate this noncollusive outcome with a superscript '*'.

\section{3 | COLLUSION}

We now proceed by considering the possibility of firms colluding on supra-competitive prices. In the following, four scenarios are studied: (1) segment-wide collusion in the low-quality submarket only, (2) segment-wide collusion in the high-quality submarket only, (3) segmentwide collusion in both submarkets separately and simultaneously, and (4) industry-wide collusion. For all these cases, we characterize the optimal collusive contract under the assumption that conspirators' aim is to maximize joint profits. Collusion is sustained through a grim trigger strategy so that any deviation from the agreement results in infinite reversion to the static Nash equilibrium by all cartel members.

Before proceeding, let us first discuss the deviating strategy in more detail. Notice first that, given the profitability of the cartel, it never pays to cheat by lifting the price since this would leave the deviant firm with no demand. Next, shaving price slightly below the collusive segment price would yield $100 \%$ of the sales in this particular submarket. However, whether this is the optimal deviating strategy depends on the best-reply toward the adjacent segment. If that 
price is lower than the collusive price, then a deviating firm finds it in its interest to follow this best-response. Consequently, for firm $i$ 's optimal deviating price $p_{i}^{d}$ it holds that $p_{i}^{d}=\min \left\{p_{i}^{c}, \widetilde{p}_{i}\right\}, i=l, h$, where $p_{i}^{c}$ indicates the collusive price and $\widetilde{p}_{i}$ is the best-reply price toward the adjacent quality segment. ${ }^{10}$

\section{1 | Partial collusion}

To begin, suppose that collusion is not industry-wide so that conspirators receive competition from firms not taking part in the agreement. Since our focus is on segment-wide collusion, a partial cartel faces one of the following two constrained maximization problems: ${ }^{11}$

$$
\begin{aligned}
& \max _{p_{l}} \frac{1}{1-\delta} \cdot\left(p_{l}-c_{l}\right) \cdot\left[\frac{v_{l} p_{h}-v_{h} p_{l}}{\left(v_{h}-v_{l}\right) v_{l}}\right] \text { subject to } \\
& \delta \geq \delta_{l}^{*} \equiv 1-\frac{1}{l} \cdot \frac{\left(p_{l}-c_{l}\right)\left(v_{l} p_{h}-v_{h} p_{l}\right)}{\left(p_{l}^{d}-c_{l}\right)\left(v_{l} p_{h}-v_{h} p_{l}^{d}\right)}
\end{aligned}
$$

or

$$
\begin{aligned}
& \max _{p_{h}} \frac{1}{1-\delta} \cdot\left(p_{h}-c_{h}\right) \cdot\left[\frac{v_{h}-v_{l}-\left(p_{h}-p_{l}\right)}{v_{h}-v_{l}}\right] \text { subject to } \\
& \delta \geq \delta_{h}^{*} \equiv 1-\frac{1}{h} \cdot \frac{\left(p_{h}-c_{h}\right)\left(v_{h}-v_{l}-\left(p_{h}-p_{l}\right)\right)}{\left(p_{h}^{d}-c_{h}\right)\left(v_{h}-v_{l}-p_{h}^{d}+p_{l}\right)}
\end{aligned}
$$

The next proposition specifies optimal prices in the event of a standard segment partial cartel, a premium segment partial cartel, and a partial cartel in both segments simultaneously. The superscript indicates the type of price-fixing conspiracy under consideration.

Proposition 1. If there is a price cartel in the standard segment only, then

$$
\begin{aligned}
& p_{l}^{l}=\frac{v_{l}}{2 v_{h}} c_{h}+\frac{1}{2} c_{l}, \\
& p_{h}^{l}=c_{h} .
\end{aligned}
$$

\footnotetext{
${ }^{10}$ Note that when $\widetilde{p}_{i}>p_{i}^{c}, p_{i}^{d}$ should, strictly speaking, be the maximum price below $p_{i}^{c}$. Yet, this is problematic since action sets are continuous in our model. We therefore follow the convention by simply writing $p_{i}^{d}=p_{i}^{c}$ in this case, which effectively means that the deviant seller prices arbitrarily close to $p_{i}^{c}$ and obtains all demand in the respective market segment(s). See, amongst many others, Tirole (1988), Bos and Harrington (2010), and De Roos and Smirnov (2020).

${ }^{11}$ The critical discount factor $\delta_{l}^{*}$ is obtained by rearranging the following incentive compatibility constraint:

$$
\frac{1}{1-\delta} \cdot\left(p_{l}-c_{l}\right) \cdot \frac{v_{l} p_{h}-v_{h} p_{l}}{l\left(v_{h}-v_{l}\right) v_{l}} \geq\left(p_{l}^{d}-c_{l}\right) \cdot \frac{v_{l} p_{h}-v_{h} p_{l}^{d}}{\left(v_{h}-v_{l}\right) v_{l}}
$$
}

The critical discount factor $\delta_{h}^{*}$ can be derived in a similar fashion. 
If there is a price cartel in the premium segment only, then

$$
\begin{aligned}
& p_{l}^{h}=c_{l}, \\
& p_{h}^{h}=\frac{v_{h}-v_{l}+c_{l}+c_{h}}{2} .
\end{aligned}
$$

If there is a price cartel in the standard segment and in the premium segment, then

$$
\begin{aligned}
& p_{l}^{l h}=\frac{\left(v_{h}-v_{l}\right) v_{l}+2 v_{h} c_{l}+v_{l} c_{h}}{4 v_{h}-v_{l}}, \\
& p_{h}^{l h}=\frac{2\left(v_{h}-v_{l}\right) v_{h}+v_{h} c_{l}+2 v_{h} c_{h}}{4 v_{h}-v_{l}} .
\end{aligned}
$$

As a first observation, note that there is a single optimum in all three scenarios. Specifically, if some collusion is feasible, then the partial cartel is capable of sustaining the joint profit maximum. The reason is that the profit-maximizing price is a best-response to the price set in the adjacent quality segment. This means that the optimal deviating strategy is to undercut the cartel price by the smallest possible amount, that is, $p_{i}^{d}=p_{i}^{c}, i=l, h$. In turn, this has the implication that the incentive compatibility constraints reduce to

$$
\begin{aligned}
& \delta \geq \delta_{l}^{*}=1-\frac{1}{l} \quad \text { and } \\
& \delta \geq \delta_{h}^{*}=1-\frac{1}{h}
\end{aligned}
$$

Thus, the unconstrained solution is feasible whenever some collusion is sustainable. Given a high enough discount factor, the latter requires the number of firms in the segment to be sufficiently small. ${ }^{12}$

Next, it can be easily verified that cartel prices are higher when firms in the adjacent segment are also colluding, which is due to the strategic complementarity of the choice variables. In terms of comparative statics, cartel prices are rising with unit production costs in both segments. Moreover, in case of a single segment-wide partial cartel, prices are increasing with the own quality level and decreasing with the quality offered in the noncollusive segment.

Yet, the effect of changes in quality is more subtle when there are two partial cartels. Similar to the case of a single segment-wide cartel, the collusive price of the premium product is increasing in $v_{h}$ and decreasing in $v_{l}$. This is less straightforward in the standard segment, however. To see this, note that

$$
\begin{aligned}
& \frac{d p_{l}^{l h}}{d v_{l}}=\frac{\partial p_{l}^{l h}}{\partial v_{l}}+\frac{\partial p_{l}^{l h}}{\partial p_{h}^{l h}} \cdot \frac{d p_{h}^{l h}}{d v_{l}}=\frac{\left(4 v_{h}-v_{l}\right) \cdot\left(v_{h}-2 v_{l}+c_{h}\right)+\left(v_{h}-v_{l}\right) v_{l}+2 v_{h} c_{l}+v_{l} c_{h}}{\left(4 v_{h}-v_{l}\right)^{2}} \\
& \frac{d p_{l}^{l h}}{d v_{h}}=\frac{\partial p_{l}^{l h}}{\partial v_{h}}+\frac{\partial p_{l}^{l h}}{\partial p_{h}^{l h}} \cdot \frac{d p_{h}^{l h}}{d v_{h}}=\frac{\left(4 v_{h}-v_{l}\right) \cdot\left(v_{l}+2 c_{l}\right)-4\left(v_{h}-v_{l}\right) v_{l}-8 v_{h} c_{l}-4 v_{l} c_{h}}{\left(4 v_{h}-v_{l}\right)^{2}}
\end{aligned}
$$

Hence, $d p_{l}^{l h} / d v_{l}<0$ and $d p_{l}^{l h} / d v_{h}>0$ when unit costs are (approximately) zero and the quality difference, $v_{h}-v_{l}$, is small enough. In both cases, the sign of the direct effect is as

\footnotetext{
${ }^{12}$ In our analysis, the number of firms is taken as given. Garcia et al. (2000) show how firms may purposely reduce the number of industry players through mergers and acquisitions to facilitate collusion.
} 
expected $\left(\partial p_{l}^{l h} / \partial v_{l}>0\right.$ and $\left.\partial p_{l}^{l h} / \partial v_{h}<0\right)$. However, the indirect (or strategic) effect may work in the opposite direction $\left(\partial p_{l}^{l h} / \partial p_{h}^{l h} \cdot d p_{h}^{l h} / d v_{l}<0\right.$ and $\left.\partial p_{l}^{l h} / \partial p_{h}^{l h} \cdot d p_{h}^{l h} / d v_{h}>0\right)$ and dominates the direct effect when the situation is sufficiently symmetric.

We conclude this subsection by considering the shifts in market shares resulting from partial collusion. Let $s_{l}$ and $s_{h}$ indicate the sales share of the standard and premium segment, respectively. The next result shows how the size of the respective segments changes under the different (partial) collusive scenarios.

Corollary 1. If there is a price cartel in the standard segment only, then

$$
\begin{aligned}
& s_{l}^{l}<s_{l}^{*}, \\
& s_{h}^{l}>s_{h}^{*} .
\end{aligned}
$$

If there is a price cartel in the premium segment only, then

$$
\begin{aligned}
& s_{l}^{l}>s_{l}^{*}, \\
& s_{h}^{l}<s_{h}^{*} .
\end{aligned}
$$

If there is a price cartel in the standard segment and in the premium segment, then

$$
\begin{aligned}
& s_{l}^{l h}<s_{l}^{*} \text { and } s_{h}^{l h}>s_{h}^{*} \text { when }\left(v_{l}-c_{l}\right) s_{l}^{*}>\left(v_{h}-c_{h}\right) s_{h}^{*}, \\
& s_{l}^{l h}>s_{l}^{*} \text { and } s_{h}^{l h}<s_{h}^{*} \text { when }\left(v_{l}-c_{l}\right) s_{l}^{*}<\left(v_{h}-c_{h}\right) s_{h}^{*} .
\end{aligned}
$$

The change in market shares in case of a single segment-wide cartel is in line with the existing literature. Theoretical work on incomplete cartels robustly predict a decrease in demand for the colluding firms' products and an increase in demand for noncartel suppliers. ${ }^{13}$ The Corollary reveals that the standard and premium segment partial cartels not only lose buyers in absolute terms, but also in relative terms, that is, their share of total sales decreases.

In case of two partial cartels, the change in market share depends on the segment sizes absent collusion as well as the value created. If, say, the premium segment is relatively small and it is relatively costly to provide additional quality (i.e., both $s_{h}^{*}$ and $v_{h}-c_{h}$ are 'small' and $s_{l}^{*}$ and $v_{l}-c_{l}$ are 'large'), then the price increase in the premium segment is smaller than in the standard segment. The strong market position of the sellers in the standard segment allows them to raise their price significantly. By contrast, the weak market position of the premium suppliers limits the scope for a price increase. Since in this case it holds that $p_{l}^{l h}-c_{l}>p_{h}^{l h}-c_{h}$, some buyers move from the standard to the premium segment so that high-quality suppliers gain back some market share.

\footnotetext{
${ }^{13}$ See, for example, De Roos (2001), Bos and Harrington (2010), Inderst et al. (2014), Currarini and Marini (2015) as well as the references therein.
} 


\section{2 | Full collusion}

We now direct our attention to the possibility of an all-inclusive cartel. In comparison to the partial cartel cases that we have analyzed above, such a collusive contract is more sophisticated in the sense that the anticompetitive combination has to simultaneously select a price for both segments. Formally, the industry-wide cartel faces the following constrained optimization problem:

$$
\begin{aligned}
& \max _{p_{l}, p_{h}} \frac{1}{1-\delta} \cdot\left[\left(p_{h}-c_{h}\right) \cdot \frac{v_{h}-v_{l}-p_{h}+p_{l}}{v_{h}-v_{l}}+\left(p_{l}-c_{l}\right) \cdot \frac{v_{l} p_{h}-v_{h} p_{l}}{\left(v_{h}-v_{l}\right) v_{l}}\right] \text { subject to } \\
& \delta \geq \delta_{l}^{*} \equiv 1-\frac{1}{l} \cdot \frac{\left(p_{l}-c_{l}\right)\left(v_{l} p_{h}-v_{h} p_{l}\right)}{\left(p_{l}^{d}-c_{l}\right)\left(v_{l} p_{h}-v_{h} p_{l}^{d}\right)}, \quad \text { and } \\
& \delta \geq \delta_{h}^{*} \equiv 1-\frac{1}{h} \cdot \frac{\left(p_{h}-c_{h}\right)\left(v_{h}-v_{l}-\left(p_{h}-p_{l}\right)\right)}{\left(p_{h}^{d}-c_{h}\right)\left(v_{h}-v_{l}-p_{h}^{d}+p_{l}\right)}
\end{aligned}
$$

This a priori allows for a plethora of cartel contracts in which none, some or all of the incentive constraints are binding. The next result restricts the set of collusive outcomes, however, by showing that all incentive constraints bind when the unconstrained solution cannot be sustained. In stating this result, let $\widetilde{\delta} \equiv \max \left\{1-\frac{1}{l}, 1-\frac{1}{h}\right\}$.

Lemma 1. Assume $\delta>\widetilde{\delta}$. If the industry-wide cartel cannot sustain the joint profit maximum, then it chooses $p_{l}$ and $p_{h}$ so that both incentive constraints bind: $\delta=\delta_{l}^{*}\left(p_{l}, p_{h}\right)=\delta_{h}^{*}\left(p_{l}, p_{h}\right)$.

This finding basically leaves two types of collusive outcome. Either all incentive constraints bind or the industry-wide cartel sets the 'unconstrained' monopoly prices $\left(p_{l}^{m}=\left(v_{l}+c_{l}\right) / 2\right.$ and $\left.p_{h}^{m}=\left(v_{h}+c_{h}\right) / 2\right)$. Note that the all-inclusive cartel could always mimic the two partial cartels case of Proposition 1 whenever some collusion is sustainable. Yet, it is willing and able to raise prices further provided that firms are sufficiently patient. In fact, and as the next proposition reveals, there is a whole range of prices that may result from industry-wide collusion. We use the superscript ' $a$ ' to indicate the all-inclusive price-fixing agreement.

Proposition 2. If there is an industry-wide price cartel, then

$$
\begin{aligned}
& p_{l}^{a} \in\left[p_{l}^{l h}, p_{l}^{m}\right] \text { and } \\
& p_{h}^{a} \in\left[p_{h}^{l h}, p_{h}^{m}\right] .
\end{aligned}
$$

What prices emerge under industry-wide collusion effectively depends on the level of the discount factor. The all-inclusive cartel can sustain the joint profit maximum when the discount factor is sufficiently high. Specifically, the most profitable outcome is feasible when

$$
\delta \geq \hat{\delta} \equiv \max \left\{\delta_{l}^{* *}, \delta_{h}^{* *}\right\}, \quad \text { where }
$$




$$
\delta_{l}^{* *}=1-\frac{1}{l} \cdot \frac{\left(v_{h} v_{l}-v_{h} c_{l}\right) \cdot\left(v_{l} c_{h}-v_{h} c_{l}\right)}{\left(v_{h} v_{l}-v_{h} c_{l}\right) \cdot\left(v_{l} c_{h}-v_{h} c_{l}\right)+\frac{1}{4}\left(v_{h} v_{l}-v_{l} c_{h}\right)^{2}}
$$

and

$$
\delta_{h}^{* *}=1-\frac{1}{h} \cdot \frac{\left(v_{h}-c_{h}\right)^{2}-\left(v_{h}-c_{h}\right) \cdot\left(v_{l}-c_{l}\right)}{\left(v_{h}-c_{h}\right)^{2}-\left(v_{h}-c_{h}\right) \cdot\left(v_{l}-c_{l}\right)+\frac{1}{4}\left(v_{l}-c_{l}\right)^{2}}
$$

Observe that $\delta_{l}^{* *}>1-\frac{1}{l}$ and $\delta_{h}^{* *}>1-\frac{1}{h}$ so that the all-encompassing cartel sets prices below monopoly levels when $\delta \in[\widetilde{\delta}, \widehat{\delta})$.

The previous result presents the profit-maximizing prices. Assuming the joint profit maximum, the following proposition specifies the profit-maximizing production level for each cartel participant.

Proposition 3. Assume an industry-wide cartel and suppose that $\delta \geq \widehat{\delta}$. Each participant produces precisely half its Nash demand:

$$
\begin{aligned}
& D_{l}^{a}=\frac{1}{2} D_{l}^{*}, \\
& D_{h}^{a}=\frac{1}{2} D_{h}^{*} .
\end{aligned}
$$

The industry-wide cartel effectively operates as a multiproduct monopolist, which implies that all price effects are internalized. In comparison to the partial cartel cases, marginal revenue of a price increase in the low-quality segment is now larger since a share of the lost low-quality sales transfer to fellow cartel members in the high-quality segment. In fact, one can verify that $p_{h}^{a}-p_{l}^{a}>p_{h}^{*}-p_{l}^{*}$ so that the industry-wide cartel raises price more in the premium segment. Proposition 3 shows that when the incentive constraints are nonbinding, the collusive marginal revenue equals marginal cost precisely when $p_{l}^{a}$ and $p_{h}^{a}$ are set such that each firm cuts its competitive output in half. ${ }^{14}$ Much like a multiproduct monopolist, therefore, an all-inclusive cartel prefers to give up selling to the group of buyers with a limited valuation of quality.

The next result follows almost immediately.

Corollary 2. Assume an industry-wide cartel and suppose that $\delta \geq \widehat{\delta}$. All market shares are maintained at precollusive levels.

This is a remarkable result for at least two reasons. First, we have studied full collusion under quality differentiation elsewhere assuming that the industry-wide cartel maintains market shares at precollusive levels. ${ }^{15}$ This finding shows that the cartel may find it in its interest to select this market division scheme when collusion spans several quality-segments simultaneously. Second, the literature on collusion in vertically differentiated markets has repeatedly shown that it may well be optimal to

\footnotetext{
${ }^{14}$ This finding is reminiscent of a well-known result in the multiproduct monopoly literature, namely that a monopolist serves half the market that would be served by a social planner. See, for example, Mussa and Rosen (1978) and Lambertini (1997).

${ }^{15}$ See Bos and Marini (2019).
} 
price lower-quality products out of the market. ${ }^{16}$ Such a strategy is suboptimal within our setting due to the substantial difference in production costs (as specified by Assumption 1). Indeed, and in line with the existing literature, it would be optimal to exclusively sell the premium product when the cost difference is sufficiently small.

\section{4 | WELFARE}

Section 3 provides a complete characterization of collusive pricing for the different types of cartel agreement. Let us now turn to the welfare consequences.

In the following, we show that an industry-wide cartel is (weakly) more harmful than any of the partial cartel scenarios for both consumers and society as a whole. If the incentive constraints bind at $\delta=\widetilde{\delta}$, then it is as detrimental as two segment-wide cartels because it can do no better than mimicking this case. For $\delta>\widetilde{\delta}$, full collusion creates more damage since then the industry-wide cartel sets higher segment prices than a segment-wide cartel. Specifically, both consumer and total surplus decline gradually when both segment prices continuously increase along the intervals as specified in Proposition 2.

Regarding the segment-wide cartel scenarios, recall that each partial cartel can sustain the joint profit-maximizing price, whenever some collusion is sustainable (Proposition 1). This implies that their welfare impact is independent of the level of the discount factor. Rather, and as will become clear in the ensuing analysis, which of the partial cartel cases is more detrimental to consumers and society as a whole effectively depends on the costs of producing (additional) quality.

We start with analyzing the impact on consumer welfare and then proceed by examining the effect on societal surplus.

\section{1 | Consumer surplus}

How are consumers affected by the different types of price-fixing agreement? To answer this question, we begin by presenting the benchmark of no collusion. Recall that the static Nash equilibrium has all firms price at marginal cost. In this case, therefore, a buyer who is indifferent between staying at home and purchasing the low-quality item is 'located' at $\theta_{0}^{*}=c_{l} / v_{l}$. A consumer who is indifferent between the standard and the premium product is at $\theta_{1}^{*}=$ $\left(c_{h}-c_{l}\right) /\left(v_{h}-v_{l}\right)$. Combining gives the (net) consumer surplus (henceforth $C S$ ):

$$
\begin{aligned}
C S^{*} & =\int_{\theta_{0}^{*}}^{1} U(\theta) d \theta=\int_{c_{l} / v_{l}}^{\frac{\left(c_{h}-c_{l}\right)}{\left(v_{h}-v_{l}\right)}}\left(\theta \cdot v_{l}\right) d \theta-c_{l} \cdot l \cdot D_{l}+\int_{\frac{\left(c_{h}-c_{l}\right)}{\left(v_{h}-v_{l}\right)}}^{1}\left(\theta \cdot v_{h}\right) d \theta-c_{h} \cdot h \cdot D_{h} \\
& =\frac{\left(v_{h}-2 c_{h}\right) \cdot\left(v_{h}-v_{l}\right)+\left(c_{h}-c_{l}\right)^{2}+\left(\frac{v_{h}-v_{l}}{v_{l}}\right) \cdot c_{l}^{2}}{2\left(v_{h}-v_{l}\right)},
\end{aligned}
$$

which is decreasing in price $\left(c_{l}\right.$ and $\left.c_{h}\right)$ and increasing in quality $\left(v_{l}\right.$ and $\left.v_{h}\right)$.

\footnotetext{
${ }^{16}$ See, for example, Bos et al. (2020). An overview of this literature is provided by Marini (2018). In fact, as total market demand is inversely related to the price of the standard product, this market share allocation implies that the price increase is larger in the premium segment.
} 
Now consider the four collusive scenarios studied above. For any of these cases, consumer surplus is generally given by

$$
C S=\int_{\theta_{0}}^{1} U(\theta) d \theta=\int_{\frac{p_{l}}{v_{l}}}^{\frac{p_{h}-p_{l}}{v_{h}-v_{l}}}\left(\theta \cdot v_{l}\right) d \theta-p_{l} \cdot l \cdot D_{l}+\int_{\frac{p_{h}-p_{l}}{v_{h}-v_{l}}}^{1}\left(\theta \cdot v_{h}\right) d \theta-p_{h} \cdot h \cdot D_{h} .
$$

By Propositions 1 and 2, we know that prices differ for the different cartel regimes. The next result shows how the various price-fixing agreements rank in terms of their impact on consumer welfare. To facilitate comparison between the different scenarios, we assume without loss of generality that $c_{l}=0$ and $c=c_{h}-c_{l}$.

Proposition 4. There is a threshold $k \in(0,1)$ such that

(i) If $c /\left(v_{h}-v_{l}\right)<k$, then

$$
C S^{*}>C S^{l}>C S^{h}>C S^{l h} \geq C S^{a} \text {, and }
$$

(ii) If $c /\left(v_{h}-v_{l}\right)>k$, then

$$
C S^{*}>C S^{h}>C S^{l}>C S^{l h} \geq C S^{a} .
$$

Not surprisingly, collusion is bad for buyers. The industry-wide cartel is the most harmful and, also in line with expectations, the scenario of two segment-wide partial cartels is second worst. The ranking of single segment-wide cartels is sensitive to differences in costs and quality, however. Specifically, if a substantial-quality improvement can be obtained for little additional cost, then a partial cartel in the premium segment is more detrimental to consumers. By contrast, a single partial cartel in the standard segment is more harmful when unit costs rise sufficiently with quality.

To see the intuition behind this latter result consider two extreme scenarios. If $c /\left(v_{h}-v_{l}\right) \rightarrow 0$, then low-quality firms are unable to effectively compete with their high-quality rivals, either in competition or under collusion. In this case, premium suppliers offer a superior value proposition even when $p_{l}=c_{l}=0$. A cost difference is thus necessary for a standard segment-wide cartel to be viable and raise price to supra-competitive levels. More generally, the impact of such a cartel on consumer welfare remains limited when low-quality suppliers have a relatively weak market position as reflected by a low $c$ or a high $v_{h}-v_{l}$.

By contrast, if $c /\left(v_{h}-v_{l}\right) \rightarrow 1$, then a partial cartel in the standard segment increases its price substantially above costs. This not only induces some customers to switch from the standard to the premium segment, but it also makes some buyers leave the market. Note that the latter effect is not present when there is a single partial cartel in the premium segment. As part (ii) of Proposition 4 reveals, this reduction in market size may be sufficiently strong to make consumers worse off with a cartel in the standard segment. 


\section{2 | Social welfare}

What about the welfare of society as a whole? How do the various types of cartel agreement affect societal surplus? To address this issue, we shall evaluate the following general social welfare function:

$$
\begin{aligned}
S W\left(p_{l}, p_{h}\right)= & \int_{\frac{p_{l}}{v_{l}}}^{\frac{r_{h}-\frac{r l}{v_{h}}}{v_{l}}}\left(\theta \cdot v_{l}\right) d \theta-c_{l} \cdot\left(\frac{p_{h}-p_{l}}{v_{h}-v_{l}}-\frac{p_{l}}{v_{l}}\right)+\int_{\frac{p_{h}-p_{l}}{v_{h}-v_{l}}}^{1}\left(\theta \cdot v_{h}\right) d \theta \\
& -c_{h} \cdot\left(1-\frac{p_{h}-p_{l}}{v_{h}-v_{l}}\right) .
\end{aligned}
$$

As established in Propositions 1 and 2, prices will differ for the different scenarios, and consequently so will societal surplus.

We start the comparison with the next proposition, which reveals the preference of a social planner.

Proposition 5. A Social Planner would charge prices equal to marginal costs:

$$
p_{l}=c_{l} \text { and } p_{h}=c_{h} \text {. }
$$

Since prices are set at marginal costs in both segments absent collusion and each cartel raises price above costs, the implication of this result is that social welfare is highest when there is no cartel. Not surprisingly, therefore, a social planner prefers a competitive world.

Let us now turn to the other extreme; an industry-wide cartel. As before, we assume without loss of generality that $c_{l}=0$ and $c=c_{h}-c_{l}$ to facilitate comparison between the different scenarios.

Proposition 6. Social welfare under all forms of partial collusion is (weakly) higher than with an industry-wide cartel.

This result confirms the intuition of an all-inclusive price-fixing cartel being most detrimental to society as a whole. As the proof in the appendix reveals, this holds both when the incentive constraints are binding and when the industry-wide cartel is capable of sustaining the monopoly solution. In fact, societal surplus monotonically declines gradually when both segment prices continuously increase along the intervals as specified in Proposition 2.

As the next proposition shows, the same does not hold for partial cartels.

Proposition 7. Define $\rho \equiv \sqrt{2} / 2+3 / 4$.

(i) If the quality ratio between the premium and standard product is $v_{h} / v_{l}=\rho$, then there exists a unique threshold $k \in(0,1)$ such that:

$$
\begin{aligned}
& \text { if } c /\left(v_{h}-v_{l}\right)<k \text {, then } S W^{l}>S W^{l h}>S W^{h}, \\
& \text { if } c /\left(v_{h}-v_{l}\right)>k \text {, then } S W^{h}>S W^{l h}>S W^{l} \text {. }
\end{aligned}
$$


(ii) If the quality ratio between the premium and standard product is $v_{h} / v_{l}>\rho$, then there exist three distinct thresholds $k_{1}, k_{2}, k_{3} \in(0,1)$ with $k_{3}>k_{2}>k_{1}$, such that:

$$
\begin{aligned}
& \text { if } c /\left(v_{h}-v_{l}\right) \in\left(0, k_{1}\right) \text {, then } S W^{l}>S W^{l h}>S W^{h}, \\
& \text { if } c /\left(v_{h}-v_{l}\right) \in\left(k_{1}, k_{2}\right) \text {, then } S W^{l}>S W^{h}>S W^{l h}, \\
& \text { if } c /\left(v_{h}-v_{l}\right) \in\left(k_{2}, k_{3}\right) \text {, then } S W^{h}>S W^{l}>S W^{l h}, \\
& \text { if } c /\left(v_{h}-v_{l}\right) \in\left(k_{3}, 1\right) \text {, then } S W^{h}>S W^{l h}>S W^{l} \text {. }
\end{aligned}
$$

(iii) If the quality ratio between the premium and standard product is $v_{h} / v_{l}<\rho$, then there exist three thresholds $k_{1}, k_{2}, k_{3} \in(0,1)$, with $k_{1}>k_{2}>k_{3}$, such that:

$$
\begin{aligned}
& \text { if } c /\left(v_{h}-v_{l}\right) \in\left(0, k_{3}\right) \text {, then } S W^{l}>S W^{l h}>S W^{h}, \\
& \text { if } c /\left(v_{h}-v_{l}\right) \in\left(k_{3}, k_{2}\right) \text {, then } S W^{l h}>S W^{l}>S W^{h}, \\
& \text { if } c /\left(v_{h}-v_{l}\right) \in\left(k_{2}, k_{1}\right) \text {, then } S W^{l h}>S W^{h}>S W^{l}, \\
& \text { if } c /\left(v_{h}-v_{l}\right) \in\left(k_{1}, 1\right) \text {, then } S W^{h}>S W^{l h}>S W^{l} .
\end{aligned}
$$

This result reveals that the impact of partial cartels on societal surplus is everything but trivial. In fact, each partial collusion scenario can be most or least detrimental to society and two cartels can be better than one.

To explain the intuition underlying this finding it is useful to distinguish between two distinct effects: a market size effect and a market share effect. The first captures the impact on social welfare that comes from a reduction in market size due to a raise in the standard segment price. It can be easily verified that the magnitude is increasing in the price of the low-quality product. This implies that it is lowest for a single premium segment-wide cartel (in fact, it is zero because in that case $p_{l}=c_{l}$ like in competition) and highest in case of two partial cartels. Note further that this effect is weakly negative so that absent any other effect we would have $S W^{h}>S W^{l}>S W^{l h}$.

Yet, there is a second effect that is driven by a shift in market shares. This market share effect captures the extent to which buyers are induced to switch to the segment generating most value. Following Assumption 1, the value created is higher in the premium segment. Hence, collusion may positively affect societal surplus by incentivizing consumers of standard products to switch to the premium segment.

With these two concepts in mind, let us now compare social welfare in case of a single partial cartel: $S W^{h}$ and $S W^{l}$. To start, note that the market size effect is zero in case of a single premium cartel. Moreover, the price rise in the premium segment induces some buyers to move to the standard segment so that the market share effect is negative. A single standard segment-wide cartel is worse in terms of the market size effect since it is strictly negative. At the same time, however, it incentivizes buyers to move to the premium segment so that the market share effect is positive. Proposition 7 shows that this positive market share effect sufficiently mitigates the negative market size effect when the cost difference is sufficiently low and the quality gap is sufficiently high. In other words, a single cartel in the premium segment is more detrimental to society than a single cartel in the standard segment when the 
value created in the premium segment, $v_{h}-c_{h}$, is significantly higher than each firm cuts its competitive output in half, $v_{l}-c_{l}{ }^{17}$

With regard to the two partial cartels scenario, note that compared with a single premium cartel the negative market size effect is stronger since the standard segment price is higher $\left(p_{l}^{l h}>p_{l}^{h}\right)$. The market share effect is less negative, however. The above result reveals that the market size effect dominates the market share effect when the marginal production costs of quality are high. In that case, the difference in value created between segments is limited and $S W^{h}>S W^{l h}$. By contrast, the market share effect may dominate the market size effect when marginal production costs of quality are low in which case it holds that $S W^{l h}>S W^{h}$.

Finally, comparing the two partial cartels scenario with a single segment-wide cartel in the standard segment, the former has a stronger market size effect (since $p_{l}^{l h}>p_{l}^{l}$ ). As to the market share effect, this effectively depends on the price difference between the standard and the premium quality segment. Specifically, the difference is smaller in the two partial cartel case when the marginal production costs of quality are sufficiently high:

$$
p_{h}^{l h}-p_{l}^{l h}<p_{h}^{l}-p_{l}^{l} \Leftrightarrow \frac{2 v_{h}}{\left(2 v_{h}-v_{l}\right)}<\frac{c}{\left(v_{h}-v_{l}\right)}
$$

Proposition 7 shows that the market share effect may be sufficiently strong to make a single standard segment cartel more detrimental than two segment-wide cartels.

In sum, what partial cartels are most harmful to society critically depends on the differences in cost and quality. A partial cartel in the premium (standard) segment is more detrimental to society when the difference in value created between both segments is sufficiently high (low), all else unchanged.

\section{5 | CONCLUDING REMARKS}

In many industries, firms can be grouped into more homogeneous classes based on quality. We have addressed the question of what collusion may look like in such quality-segmented markets through studying an infinitely repeated price-setting game with two submarkets: a standard and a premium quality segment. We used this framework to analyze four types of price-fixing agreement: a segment-wide cartel in the premium submarket only, a segment-wide cartel in the standard submarket only, two segment-wide cartels, one in each submarket, and an industrywide cartel. For all these cases, we provided a complete characterization of the collusive equilibrium and examined the impact on market shares and welfare.

Let us summarize some of our main findings. Whenever collusion is sustainable, partial cartels are capable of sustaining the joint profit-maximizing price. By contrast, the all-inclusive cartel can sustain the unconstrained optimum only when its members are sufficiently patient. Incomplete cartels lose market share when the segment in which they operate is sufficiently large and the industry-wide cartel prefers to set its prices to maintain market shares at precollusive levels. In terms of welfare, we show that a partial cartel in the premium segment is

\footnotetext{
${ }^{17}$ The importance of quality choice in contrast to the price choice to mitigate inefficient outcomes has been recently explored for instance in mixed duopoly markets by Klumpp and Xuejuan (2020).
} 
more detrimental to consumers than a partial cartel in the standard segment when the marginal costs of quality are sufficiently small. The impact on societal welfare also critically depends on the relation between quality and costs. Among other things, we find that a single segment-wide partial cartel may be more harmful for society than two segment-wide partial cartels.

There are three natural avenues for future research. First, it may be interesting to also allow for within-segment heterogeneity, that is, include some degree of horizontal differentiation. Second, one might explore the potential impact of additional quality segments. Both extensions will likely prove to be computationally challenging, however. Finally, we have studied price collusion given qualities. Though it seems natural to assume the available qualities to be exogenous in the short run, we can imagine situations in which the quality offered is (partly) endogenous. It is worth exploring how our main findings would be affected when allowing firms to reposition themselves along the quality spectrum. We leave this issue for future research.

\section{ACKNOWLEDGMENTS}

We appreciate the comments and discussions with David Collie, Luis Corchón, Jean Gabszewicz, Andrey Minaev, Riccardo Saulle, Attila Tasnádi, Jacques-François Thisse, participants at the Oligo Workshop in Nottingham, the editor, and an anonymous referee. All opinions and errors are ours alone. The second author gratefully acknowledges the financial support of Sapienza University of Rome and of Edgard Milhaud Foundation.

\section{ORCID}

\section{Marco A. Marini (D) https://orcid.org/0000-0002-7452-614X}

\section{REFERENCES}

Bonnet, C., \& Bouamra-Mechemache, Z. (2019). Yogurt cartel: Yogurt cartel of private label providers in France: Impact on prices and welfare (TSE Working Papers 19-1012). Toulouse School of Economics.

Bos, I., \& Harrington Jr., J. E. (2010). Endogenous cartel formation with heterogeneous firms. RAND Journal of Economics, 41(1), 92-117.

Bos, I., \& Marini, M. A. (2019). Cartel stability under quality differentiation. Economics Letters, 174, 70-73.

Bos, I., Marini, M. A., \& Saulle, R. (2020). Cartel formation with quality differentiation. Mathematical Social Sciences, 106(1), 33-50.

Currarini, S., \& Marini, M. A. (2015). Coalitional approaches to collusive agreements in oligopoly games. Manchester School, 83(3), 253-378.

De Roos, N., \& Smirnov, V. (2020). Collusion, price dispersion, and fringe competition (Working Paper). Sydney University.

De Roos, N. (2001). Collusion with a competitive fringe: An application to vitamin C (Working Paper). Yale University.

Donsimoni, M.-P. (1985). Stable heterogeneous cartels. International Journal of Industrial Organization, 3(4), 451-467.

Ecchia, G., \& Lambertini, L. (1997). Minimum quality standards and collusion. Journal of Industrial Economics, 45(1), 101-113.

Gabszewicz, J. J., \& Thisse, J.-F. (1979). Price competition, quality and income disparities. Journal of Economic Theory, 20(3), 340-359.

Garcia, F., Paz y Miño, J. M., \& Torrens, G. (2020). The merger paradox, collusion, and competition policy. Journal of Public Economic Theory, 22, 2051-2081.

Häckner, J. (1994). Collusive pricing in markets for vertically differentiated products. International Journal of Industrial Organization, 12(2), 155-177. 
Harrington Jr., J. E. (2006). How do cartels operate? Foundations and Trends in Microeconomics, 2(1), $1-105$.

Hasnas, I., \& Wey, C. (2015). Full versus partial collusion among brands and private label producers (DICE Discussion Paper 190).

Inderst, R., Maier-Rigaud, F. P., \& Schwalbe, U. (2014). Umbrella effects. Journal of Competition Law \& Economics, 10(3), 739-763.

Klumpp, T., \& Su, X. (2020). Price-quality competition in a mixed duopoly. Journal of Public Economic Theory, $21,400-432$.

Klumpp, T., \& Xuejuan, S. (2020). Price-quality competition in a mixed duopoly. Journal of Public Economic Theory, 21, 400-432.

Lambertini, L. (1997). The multi-product monopolist under vertical differentiation: An inductive approach. Recherches Economiques de Louvain, 62(3), 109-122.

Marini, M. A. (2018). Collusive agreements in vertically differentiated markets. In L. C. Corchón, \& M. A. Marini (Eds.), Handbook of game theory and industrial organization: Applications (Vol. 2). Edward Elgar.

Mussa, M., \& Rosen, S. (1978). Monopoly and product quality. Journal of Economic Theory, 18(2), 301-317.

Schmitt, N., \& Weder, R. (1998). Sunk costs and cartel formation: Theory and application to the dyestuff industry. Journal of Economic Behavior \& Organization, 36, 197-220.

Shaked, A., \& Sutton, J. (1982). Relaxing price competition through product differentiation. Review of Economic Studies, 49(1), 3-13.

Sullivan, C. J. (2017). Three essays on product collusion (Ph.D. Dissertation). University of Michigan.

Symeonidis, G. (1999). Cartel stability in advertising-intensive and R\&D-intensive industries. Economics Letters, $62,121-129$.

Tirole, J. (1988). The theory of industrial organization. MIT Press.

How to cite this article: Bos, I., \& Marini, M. A. (2021). Collusion in quality-segmented markets. Journal of Public Economic Theory, 1-31. https://doi.org/10.1111/jpet.12558

\section{APPENDIX A: PROOFS}

Proof of Proposition 1. To start, consider a single segment-wide partial cartel in the standard segment. Such a cartel faces the following constrained maximization problem:

$$
\begin{aligned}
& \max _{p_{l}} \frac{1}{1-\delta} \cdot\left(p_{l}-c_{l}\right) \cdot \frac{v_{l} p_{h}-v_{h} p_{l}}{\left(v_{h}-v_{l}\right) v_{l}} \text { subject to } \\
& \delta \geq \delta_{l}^{*}=1-\frac{1}{l} \cdot \frac{\left(p_{l}-c_{l}\right)\left(v_{l} p_{h}-v_{h} p_{l}\right)}{\left(p_{l}^{d}-c_{l}\right)\left(v_{l} p_{h}-v_{h} p_{l}^{d}\right)}
\end{aligned}
$$

Since there is more than one firm in the adjacent premium segment, it follows from Assumptions 1 and 2 that $p_{h}=c_{h}$. This means that the joint profit-maximizing price is a best-reply to $c_{h}$, which implies $p_{l}^{d}$ is (approximately) equal to this collusive solution. The incentive compatibility constraint therefore reduces to

$$
\delta \geq \delta_{l}^{*}=1-\frac{1}{l}
$$


Consequently, the joint profit-maximizing price can be sustained whenever some collusion is sustainable. Taking the first-order condition and rearranging gives

$$
p_{l}^{l}=\frac{v_{l}}{2 v_{h}} c_{h}+\frac{1}{2} c_{l}
$$

Next, consider a single segment-wide partial cartel in the premium segment. Such a cartel faces the following constrained maximization problem:

$$
\begin{aligned}
& \max _{p_{h}} \frac{1}{1-\delta} \cdot\left(p_{h}-c_{h}\right) \cdot \frac{v_{h}-v_{l}-p_{h}+p_{l}}{v_{h}-v_{l}} \text { subject to } \\
& \delta \geq \delta_{h}^{*}=1-\frac{1}{h} \cdot \frac{\left(p_{h}-c_{h}\right)\left(v_{h}-v_{l}-p_{h}+p_{l}\right)}{\left(p_{h}^{d}-c_{h}\right)\left(v_{h}-v_{l}-p_{h}^{d}+p_{l}\right)} .
\end{aligned}
$$

Since there is more than one firm in the standard segment, it follows from Assumptions 1 and 2 that $p_{l}=c_{l}$. Similar to the previous case, the joint profit-maximizing price is a bestreply to $c_{l}$, which implies $p_{h}^{d}$ is (approximately) equal to this collusive solution. The incentive compatibility constraint therefore reduces to

$$
\delta \geq 1-\frac{1}{h}
$$

The joint profit-maximizing price can thus be sustained whenever some collusion is sustainable. Taking the first-order condition and rearranging gives

$$
p_{h}^{h}=\frac{v_{h}-v_{l}+c_{l}+c_{h}}{2}
$$

Finally, consider the possibility of a partial cartel in each segment. Also in this case, the joint profit-maximizing price is a best-response to the price set by firms in the adjacent segment. Thus, $p_{i}^{d}, i=l, h$, is again (approximately) equal to this collusive solution and the incentive constraints reduce to

$$
\delta \geq 1-\frac{1}{l} \text {, and } \delta \geq 1-\frac{1}{h}
$$

Hence, the joint profit-maximizing prices can be sustained whenever some segment-wide collusion is feasible. The collusive optimum is therefore given by the respective first-order conditions. Rearranging gives

$$
\begin{aligned}
& p_{l}^{l h}=\frac{\left(v_{h}-v_{l}\right) v_{l}+2 v_{h} c_{l}+v_{l} c_{h}}{4 v_{h}-v_{l}}, \\
& p_{h}^{l h}=\frac{2\left(v_{h}-v_{l}\right) v_{h}+v_{h} c_{l}+2 v_{h} c_{h}}{4 v_{h}-v_{l}} .
\end{aligned}
$$


Proof of Corollary 1. To begin, note that the market shares of the two segments absent collusion are given by

$$
\begin{aligned}
s_{l}^{*} & =\frac{c_{h} v_{l}-c_{l} v_{h}}{\left(v_{h}-v_{l}\right)\left(v_{l}-c_{l}\right)}, \\
s_{h}^{*} & =\frac{v_{l}\left(v_{h}-v_{l}-c_{h}+c_{l}\right)}{\left(v_{h}-v_{l}\right)\left(v_{l}-c_{l}\right)} .
\end{aligned}
$$

Using the collusive prices as specified in Proposition 1, when there is a partial cartel in the standard segment only its sales share is

$$
s_{l}^{l}=\frac{c_{h} v_{l}-p_{l}^{l} v_{h}}{\left(v_{h}-v_{l}\right)\left(v_{l}-p_{l}^{l}\right)}=\frac{v_{h}\left(c_{h} v_{l}-c_{l} v_{h}\right)}{\left(v_{h}-v_{l}\right)\left(2 v_{h} v_{l}-c_{h} v_{l}-c_{l} v_{h}\right)}
$$

which is smaller than the Nash equilibrium share when

$$
s_{l}^{l}-s_{l}^{*}=\frac{v_{h}\left(c_{h} v_{l}-c_{l} v_{h}\right)}{\left(v_{h}-v_{l}\right)\left(v_{l}\left(v_{h}-c_{h}\right)+v_{h}\left(v_{l}-c_{l}\right)\right)}-\frac{c_{h} v_{l}-c_{l} v_{h}}{\left(v_{h}-v_{l}\right)\left(v_{l}-c_{l}\right)}<0 .
$$

Rearranging gives

$$
-v_{l}\left(v_{h}-c_{h}\right)<0
$$

which holds.

Using the collusive prices as specified in Proposition 1, when there is a partial cartel in the premium segment only its sales share is

$$
s_{h}^{h}=\frac{v_{l}\left(v_{h}-v_{l}-p_{h}^{h}+c_{l}\right)}{\left(v_{h}-v_{l}\right)\left(v_{l}-c_{l}\right)}=\frac{v_{l}\left(v_{h}-v_{l}-c_{h}+c_{l}\right)}{2\left(v_{h}-v_{l}\right)\left(v_{l}-c_{l}\right)},
$$

which is smaller than the Nash equilibrium share when

$$
s_{h}^{h}-s_{h}^{*}=\frac{v_{l}\left(v_{h}-v_{l}-c_{h}+c_{l}\right)}{2\left(v_{h}-v_{l}\right)\left(v_{l}-c_{l}\right)}-\frac{v_{l}\left(v_{h}-v_{l}-c_{h}+c_{l}\right)}{\left(v_{h}-v_{l}\right)\left(v_{l}-c_{l}\right)}<0,
$$

which holds.

Finally, consider the case in which there is a partial cartel in both segments. We show that $s_{h}^{l h}>s_{h}^{*}$ when $\left(v_{l}-c_{l}\right) s_{l}^{*}>\left(v_{h}-c_{h}\right) s_{h}^{*}$. By the prices as specified in Proposition 1 , $s_{h}^{l h}$ is given by

$$
s_{h}^{l h}=\frac{v_{l}\left(v_{h}-v_{l}-p_{h}^{l h}+p_{l}^{l h}\right)}{\left(v_{h}-v_{l}\right)\left(v_{l}-p_{l}^{l h}\right)}=\frac{v_{l}\left[2 v_{h}\left(v_{h}-v_{l}\right)-2 c_{h} v_{h}+c_{h} v_{l}+c_{l} v_{h}\right]}{\left(v_{h}-v_{l}\right)\left[v_{l}\left(v_{h}-c_{h}\right)+2 v_{h}\left(v_{l}-c_{l}\right)\right]}
$$


Comparing with the Nash equilibrium share

$$
\begin{gathered}
s_{h}^{l h}>s_{h}^{*}, \\
\frac{v_{l}\left[2 v_{h}\left(v_{h}-v_{l}\right)-2 c_{h} v_{h}+c_{h} v_{l}+c_{l} v_{h}\right]}{\left(v_{h}-v_{l}\right)\left[v_{l}\left(v_{h}-c_{h}\right)+2 v_{h}\left(v_{l}-c_{l}\right)\right]}>\frac{v_{l}\left(v_{h}-v_{l}-c_{h}+c_{l}\right)}{\left(v_{h}-v_{l}\right)\left(v_{l}-c_{l}\right)} .
\end{gathered}
$$

Rearranging and using the above specifications for $s_{l}^{*}$ and $s_{h}^{*}$ give

$$
\left(v_{l}-c_{l}\right) \cdot s_{l}^{*}>\left(v_{h}-c_{h}\right) \cdot s_{h}^{*}
$$

Hence, we conclude that if $\left(v_{l}-c_{l}\right) s_{l}^{*}>\left(v_{h}-c_{h}\right) s_{h}^{*}$, then $s_{l}^{l h}<s_{l}^{*}$ and $s_{h}^{l h}>s_{h}^{*}$ (and vice versa).

Proof of Lemma 1. To begin, note that the all-inclusive cartel could mimic the situation with two segment-wide partial cartels as specified in Proposition 1. Yet, since $\delta>\widetilde{\delta} \equiv \max \left\{1-\frac{1}{l}, 1-\frac{1}{h}\right\}$, the industry-wide cartel can improve upon this outcome. Next, recall that the joint profit-maximizing prices in the two partial cartels case are in fact best-responses to the adjacent segment. This has the implication that when the cartel increases prices further it holds that $p_{i}^{d}=\widetilde{p}_{i}, i=l, h$. That is, a deviant firm finds it optimal to not just cut its price slightly below the collusive segment price, but to lower it further to the best-reply level.

Given this deviating strategy, let us now proceed by writing down the Lagrangian of the constrained maximization problem:

$$
\begin{aligned}
L\left(p_{l}, p_{h}\right)= & \frac{1}{1-\delta} \cdot\left[\left(p_{h}-c_{h}\right) \cdot \frac{v_{h}-v_{l}-p_{h}+p_{l}}{v_{h}-v_{l}}+\left(p_{l}-c_{l}\right) \cdot \frac{v_{l} p_{h}-v_{h} p_{l}}{\left(v_{h}-v_{l}\right) v_{l}}\right] \\
& +\lambda_{1} \cdot\left[\left(p_{h}-c_{h}\right) \cdot \frac{v_{h}-v_{l}-p_{h}+p_{l}}{v_{h}-v_{l}}-(1-\delta) \cdot h \cdot \frac{\left(v_{h}-v_{l}+p_{l}-c_{h}\right)^{2}}{4\left(v_{h}-v_{l}\right)}\right] \\
& +\lambda_{2} \cdot\left[\left(p_{l}-c_{l}\right) \cdot \frac{v_{l} p_{h}-v_{h} p_{l}}{\left(v_{h}-v_{l}\right) v_{l}}-(1-\delta) \cdot l \cdot \frac{\left(v_{l} p_{h}-v_{h} c_{l}\right)^{2}}{4 v_{h}\left(v_{h}-v_{l}\right) v_{l}}\right] .
\end{aligned}
$$

The corresponding Karush-Kuhn-Tucker (KKT) conditions are

$$
\begin{aligned}
& \frac{\partial L}{\partial p_{h}}= \frac{1}{1-\delta} \cdot\left[v_{h}-v_{l}-2 p_{h}+2 p_{l}+c_{h}-c_{l}\right]+\lambda_{1} \cdot\left[v_{h}-v_{l}-2 p_{h}+p_{l}+c_{h}\right] \\
&+\lambda_{2} \cdot\left[p_{l}-c_{l}-(1-\delta) \cdot l \cdot \frac{\left(v_{l} p_{h}-v_{h} c_{l}\right)}{2 v_{h}}\right]=0, \\
& \frac{\partial L}{\partial p_{l}}= \frac{1}{1-\delta} \cdot\left[\frac{2 v_{l} p_{h}-2 v_{h} p_{l}+v_{h} c_{l}-v_{l} c_{h}}{v_{l}}\right] \\
&+\lambda_{1} \cdot\left[p_{h}-c_{h}-(1-\delta) \cdot h \cdot \frac{\left(v_{h}-v_{l}+p_{l}-c_{h}\right)}{2}\right]+\lambda_{2} \cdot\left[\frac{v_{l} p_{h}-2 v_{h} p_{l}+v_{h} c_{l}}{v_{l}}\right]=0, \\
& \lambda_{1}, \lambda_{2} \geq 0 \\
& \lambda_{1} \cdot\left[\left(p_{h}-c_{h}\right) \cdot\left(v_{h}-v_{l}-p_{h}+p_{l}\right)-(1-\delta) \cdot h \cdot \frac{\left(v_{h}-v_{l}+p_{l}-c_{h}\right)^{2}}{4}\right]=0, \\
& \lambda_{2} \cdot\left[\left(p_{l}-c_{l}\right) \cdot\left(v_{l} p_{h}-v_{h} p_{l}\right)-(1-\delta) \cdot l \cdot \frac{\left(v_{l} p_{h}-v_{h} c_{l}\right)^{2}}{4 v_{h}}\right]=0 .
\end{aligned}
$$


To show that all incentive constraints must be binding when the joint profit maximum cannot be sustained, we consider two cases: (i) the incentive constraints of all highquality firms are binding, whereas the incentive constraints of the low-quality firms are not and (ii) the incentive constraints of all low-quality firms are binding, whereas the incentive constraints of the high-quality firms are not. For both cases, we derive a contradiction.

Case (i): $\lambda_{1}>0$ and $\lambda_{2}=0$. In this case, the KKT conditions reduce to

$$
\begin{gathered}
\frac{\partial L}{\partial p_{h}}=\frac{1}{1-\delta} \cdot\left[v_{h}-v_{l}-2 p_{h}+2 p_{l}+c_{h}-c_{l}\right]+\lambda_{1} \cdot\left[v_{h}-v_{l}-2 p_{h}+p_{l}+c_{h}\right]=0, \\
\frac{\partial L}{\partial p_{l}}=\frac{1}{1-\delta} \cdot\left[\frac{2 v_{l} p_{h}-2 v_{h} p_{l}+v_{h} c_{l}-v_{l} c_{h}}{v_{l}}\right] \\
+\lambda_{1} \cdot\left[p_{h}-c_{h}-(1-\delta) \cdot h \cdot \frac{\left(v_{h}-v_{l}+p_{l}-c_{h}\right)}{2}\right]=0, \\
\lambda_{1}>0, \lambda_{2}=0, \\
\lambda_{1} \cdot\left[\left(p_{h}-c_{h}\right) \cdot\left(v_{h}-v_{l}-p_{h}+p_{l}\right)-(1-\delta) \cdot h \cdot \frac{\left(v_{h}-v_{l}+p_{l}-c_{h}\right)^{2}}{4}\right]=0 .
\end{gathered}
$$

As the price of the basic good is unconstrained, we know that

$$
\frac{2 v_{l} p_{h}-2 v_{h} p_{l}+v_{h} c_{l}-v_{l} c_{h}}{v_{l}}=0 .
$$

Hence, by the second KKT condition it must hold that

$$
p_{h}-c_{h}-(1-\delta) \cdot h \cdot \frac{\left(v_{h}-v_{l}+p_{l}-c_{h}\right)}{2}=0
$$

whereas by the last KKT condition, we know

$$
\begin{gathered}
\left(p_{h}-c_{h}\right) \cdot\left(v_{h}-v_{l}-p_{h}+p_{l}\right)-(1-\delta) \cdot h \cdot \frac{\left(v_{h}-v_{l}+p_{l}-c_{h}\right)^{2}}{4}=0 \\
\Leftrightarrow p_{h}-c_{h}=(1-\delta) \cdot h \cdot \frac{\left(v_{h}-v_{l}+p_{l}-c_{h}\right)^{2}}{4\left(v_{h}-v_{l}-p_{h}+p_{l}\right)} .
\end{gathered}
$$

Combining gives

$$
(1-\delta) \cdot h \cdot \frac{\left(v_{h}-v_{l}+p_{l}-c_{h}\right)^{2}}{4\left(v_{h}-v_{l}-p_{h}+p_{l}\right)}-(1-\delta) \cdot h \cdot \frac{\left(v_{h}-v_{l}+p_{l}-c_{h}\right)}{2}=0
$$

or

$$
v_{h}-v_{l}-2 p_{h}+p_{l}+c_{h}=0 \text {. }
$$


Combining with the first KKT condition, this implies

$$
v_{h}-v_{l}-2 p_{h}+p_{l}+c_{h}+p_{l}-c_{l}=0,
$$

which cannot hold as $p_{l}>c_{l}$ under collusion; a contradiction.

Case (ii): $\lambda_{1}=0$ and $\lambda_{2}>0$. In this case, the KKT conditions reduce to

$$
\begin{gathered}
\frac{\partial L}{\partial p_{h}}=\frac{1}{1-\delta} \cdot\left[v_{h}-v_{l}-2 p_{h}+2 p_{l}+c_{h}-c_{l}\right] \\
+\lambda_{2} \cdot\left[p_{l}-c_{l}-(1-\delta) \cdot l \cdot \frac{\left(v_{l} p_{h}-v_{h} c_{l}\right)}{2 v_{h}}\right]=0, \\
\frac{\partial L}{\partial p_{l}}=\frac{1}{1-\delta} \cdot\left[\frac{2 v_{l} p_{h}-2 v_{h} p_{l}+v_{h} c_{l}-v_{l} c_{h}}{v_{l}}\right]+\lambda_{2} \cdot\left[\frac{v_{l} p_{h}-2 v_{h} p_{l}+v_{h} c_{l}}{v_{l}}\right]=0, \\
\lambda_{1}=0, \lambda_{2}>0, \\
\lambda_{2} \cdot\left[\left(p_{l}-c_{l}\right) \cdot\left(v_{l} p_{h}-v_{h} p_{l}\right)-(1-\delta) \cdot l \cdot \frac{\left(v_{l} p_{h}-v_{h} c_{l}\right)^{2}}{4 v_{h}}\right]=0 .
\end{gathered}
$$

As the price of the premium product is unconstrained, we know that

$$
v_{h}-v_{l}-2 p_{h}+2 p_{l}+c_{h}-c_{l}=0 \text {. }
$$

Hence, by the first KKT condition it must hold that

$$
p_{l}-c_{l}-(1-\delta) \cdot l \cdot \frac{\left(v_{l} p_{h}-v_{h} c_{l}\right)}{2 v_{h}}=0
$$

whereas by the last KKT condition, we know that

$$
\begin{gathered}
\left(p_{l}-c_{l}\right) \cdot\left(v_{l} p_{h}-v_{h} p_{l}\right)-(1-\delta) \cdot l \cdot \frac{\left(v_{l} p_{h}-v_{h} c_{l}\right)^{2}}{4 v_{h}}=0 \Leftrightarrow \\
p_{l}-c_{l}=(1-\delta) \cdot l \cdot \frac{\left(v_{l} p_{h}-v_{h} c_{l}\right)^{2}}{4 v_{h}\left(v_{l} p_{h}-v_{h} p_{l}\right)} .
\end{gathered}
$$

Combining gives

$$
(1-\delta) \cdot l \cdot \frac{\left(v_{l} p_{h}-v_{h} c_{l}\right)^{2}}{4 v_{h}\left(v_{l} p_{h}-v_{h} p_{l}\right)}-(1-\delta) \cdot l \cdot \frac{\left(v_{l} p_{h}-v_{h} c_{l}\right)}{2 v_{h}}=0
$$

or

$$
v_{l} p_{h}-2 v_{h} p_{l}+v_{h} c_{l}=0 .
$$


Combining with the second KKT condition, this implies

$$
v_{l} p_{h}-2 v_{h} p_{l}+v_{h} c_{l}+v_{l} p_{h}-v_{l} c_{h}=0
$$

which cannot hold as $p_{h}>c_{h}$ under collusion, a contradiction. We thus conclude that when a profit-maximizing industry-wide cartel sets prices below the joint profit maximum all incentive constraints must be binding.

Proof of Proposition 2. Industry-wide collusion is sustainable when

$$
\begin{aligned}
& \delta \geq \delta_{l}^{*}=1-\frac{1}{l} \cdot \frac{\left(p_{l}-c_{l}\right)\left(v_{l} p_{h}-v_{h} p_{l}\right)}{\left(p_{l}^{d}-c_{l}\right)\left(v_{l} p_{h}-v_{h} p_{l}^{d}\right)} \text { and } \\
& \delta \geq \delta_{h}^{*}=1-\frac{1}{h} \cdot \frac{\left(p_{h}-c_{h}\right)\left(v_{h}-v_{l}-p_{h}+p_{l}\right)}{\left(p_{h}^{d}-c_{h}\right)\left(v_{h}-v_{l}-p_{h}^{d}+p_{l}\right)} .
\end{aligned}
$$

To begin, the all-inclusive cartel can mimic the two partial cartels scenario as described in Proposition 1. In that case, $p_{l}^{a}=p_{l}^{d}$ and $p_{h}^{a}=p_{h}^{d}$ so that the incentive constraints reduce to

$$
\delta \geq 1-\frac{1}{l} \quad \text { and } \quad \delta \geq 1-\frac{1}{h}
$$

Thus, the industry-wide cartel can sustain the following prices whenever some collusion is sustainable:

$$
\begin{aligned}
& p_{l}^{i}=p_{l}^{l h}=\frac{\left(v_{h}-v_{l}\right) v_{l}+2 v_{h} c_{l}+v_{l} c_{h}}{4 v_{h}-v_{l}} \text { and } \\
& p_{h}^{i}=p_{h}^{l h}=\frac{2\left(v_{h}-v_{l}\right) v_{h}+v_{h} c_{l}+2 v_{h} c_{h}}{4 v_{h}-v_{l}} .
\end{aligned}
$$

This would be the outcome when $\delta=\widetilde{\delta}$.

If $\delta>\widetilde{\delta}$, then the industry-wide cartel is able and willing to raise prices further. In that case, deviating prices are a best-response to the adjacent quality segment and strictly below the collusive level. Using $p_{l}^{d}=\left(v_{l} p_{h}^{a}+v_{h} c_{l}\right) / 2 v_{h}$ and $p_{h}^{d}=\left(v_{h}-v_{l}+p_{l}^{a}+c_{h}\right) / 2$, the critical discount factors can be written as

$$
\begin{aligned}
& \delta_{l}^{*}=1-\frac{1}{l} \cdot \frac{\left(p_{l}-c_{l}\right)\left(v_{l} p_{h}-v_{h} p_{l}\right)}{\left(p_{l}^{d}-c_{l}\right)\left(v_{l} p_{h}-v_{h} p_{l}^{d}\right)}=1-\frac{1}{l} \cdot\left[\frac{2\left(p_{l}^{d}-c_{l}\right)\left(p_{l}-c_{l}\right)-\left(p_{l}-c_{l}\right)^{2}}{\left(p_{l}^{d}-c_{l}\right)^{2}}\right] \text { and } \\
& \delta_{h}^{*}=1-\frac{1}{h} \cdot \frac{\left(p_{h}-c_{h}\right)\left(v_{h}-v_{l}-p_{h}+p_{l}\right)}{\left(p_{h}^{d}-c_{h}\right)\left(v_{h}-v_{l}-p_{h}^{d}+p_{l}\right)}=1-\frac{1}{h} \cdot\left[\frac{2\left(p_{h}^{d}-c_{h}\right)\left(p_{h}-c_{h}\right)-\left(p_{h}-c_{h}\right)^{2}}{\left(p_{h}^{d}-c_{h}\right)^{2}}\right] .
\end{aligned}
$$

Note that, in both cases, the last term between brackets is strictly below 1 so that the incentive constraints are tighter than in the scenario with two partial cartels. By Lemma 1 , when collusion is constrained, the industry-wide cartel sets its prices such that $\delta=\delta_{l}^{*}=\delta_{h}^{*}$. 
Finally, if $\delta \rightarrow 1$, then none of the incentive constraints bind in which case collusive prices are given by the first-order conditions. Rearranging gives

$$
p_{l}^{a}=p_{l}^{m}=\frac{v_{l}+c_{l}}{2} \text { and } \quad p_{h}^{a}=p_{h}^{m}=\frac{v_{h}+c_{h}}{2}
$$

Proof of Proposition 3. Using the full collusive unconstrained prices as specified in Proposition 2, the profit-maximizing production levels are given by

$$
\begin{aligned}
& D_{l}^{a}=\frac{v_{l} c_{h}-v_{h} c_{l}}{2 l v_{l}\left(v_{h}-v_{l}\right)}, \\
& D_{h}^{a}=\frac{\left(v_{h}-v_{l}\right)-c_{h}+c_{l}}{2 h\left(v_{h}-v_{l}\right)},
\end{aligned}
$$

which is precisely half the Nash demand:

$$
\begin{aligned}
& D_{l}^{*}=\frac{v_{l} c_{h}-v_{h} c_{l}}{l\left(v_{h}-v_{l}\right) v_{l}}, \\
& D_{h}^{*}=\frac{\left(v_{h}-v_{l}\right)-c_{h}+c_{l}}{h\left(v_{h}-v_{l}\right)} .
\end{aligned}
$$

Proof of Corollary 2. Absent collusion, total market demand is given by

$$
D^{*}=\frac{v_{l}-c_{l}}{v_{l}} \text {. }
$$

Under full collusion at the joint profit maximum, it is

$$
D^{a}=\frac{v_{l}-c_{l}}{2 v_{l}}
$$

Combining with the results from the previous proposition, it can be easily verified that

$$
\frac{D_{i}^{a}}{D^{a}}=\frac{D_{i}^{*}}{D^{*}}, \quad \forall i \in L, H
$$

Proof of Proposition 4. To begin, note that consumer surplus can be written as

$$
\begin{aligned}
C S & =\int_{\frac{p_{l}}{v_{l}}}^{\frac{p_{h}-p_{l}}{v_{h}-v_{l}}}\left(\theta \cdot v_{l}\right) d \theta-p_{l} \cdot \frac{v_{l} p_{h}-v_{h} p_{l}}{\left(v_{h}-v_{l}\right) v_{l}}+\int_{\frac{p_{h}-p_{l}}{v_{h}-v_{l}}}^{1}\left(\theta \cdot v_{h}\right) d \theta-p_{h} \cdot \frac{v_{h}-v_{l}-p_{h}+p_{l}}{v_{h}-v_{l}} \\
& =\frac{p_{h}^{2}+\frac{v_{h}}{v_{l}} p_{l}^{2}-2 p_{h}\left(p_{l}+v_{h}-v_{l}\right)+v_{h}\left(v_{h}-v_{l}\right)}{2\left(v_{h}-v_{l}\right)},
\end{aligned}
$$

which is monotonically decreasing in both prices. Hence, all types of cartel are bad for buyers in the sense that at least one consumer pays more for the same quality and no consumer pays less. It follows that consumer surplus is highest absent collusion. Moreover, since consumer welfare is strictly decreasing in segment prices, it holds that 
$C S^{l}, C S^{h}>C S^{l h}$ (by Proposition 1) and $C S^{l h} \geq C S^{a}$ (by Proposition 2). We conclude that $C S^{*}>C S^{l}, C S^{h}>C S^{l h} \geq C S^{a}$.

Finally, let us compare $C S^{l}$ and $C S^{h}$. Combining the consumer surplus formula with the prices given in Proposition 1, one obtains

$$
\begin{aligned}
C S^{l} & =\frac{4\left(v_{h}-v_{l}\right)\left(v_{h}-c\right)^{2}+v_{l} c^{2}}{8 v_{h}\left(v_{h}-v_{l}\right)} \text { and } \\
C S^{h} & =\frac{\left(v_{h}-v_{l}\right)\left(v_{h}+3 v_{l}-2 c\right)+c^{2}}{8\left(v_{h}-v_{l}\right)} .
\end{aligned}
$$

Taking the difference yields

$$
C S^{l}-C S^{h}=\frac{3 v_{h}\left(v_{h}-v_{l}-2 c\right)+3 c^{2}}{8 v_{h}},
$$

which for $c \rightarrow 0$ reduces to

$$
\frac{3 v_{h}\left(v_{h}-v_{l}\right)}{8 v_{h}}>0
$$

Next, $C S^{l}-C S^{h}$ is convex in $c$ and negative at the upper bound, $c=v_{h}-v_{l}$ (Assumption 1):

$$
\frac{-3 v_{h}\left(v_{h}-v_{l}\right)+3\left(v_{h}-v_{l}\right)^{2}}{8 v_{h}}<0
$$

Also note that

$$
C S^{l}-C S^{h}=\frac{3 v_{h}\left(v_{h}-v_{l}-2 c\right)+3 c^{2}}{8 v_{h}}=0 \Rightarrow c^{2}-2 c v_{h}+v_{h}\left(v_{h}-v_{l}\right)=0,
$$

which has $\tilde{c}=v_{h}-\sqrt{v_{h} v_{l}}$ as the smaller root. Combining these findings then leads to the following conclusion. For a given quality gap $v_{h}-v_{l}$ : (i) if $c \in[0, \tilde{c})$, then $C S^{l}>C S^{h}$, and (ii) if $c \in\left(\tilde{c}, v_{h}-v_{l}\right)$, then $C S^{h}>C S^{l}$.

Proof of Proposition 5. First, note that social welfare is generally given by

$$
\begin{aligned}
S W\left(p_{l}, p_{h}\right)= & \int_{\frac{p_{l}}{v_{l}}}^{\frac{p_{h}-\frac{r l}{v_{h}}}{v_{l}}}\left(\theta \cdot v_{l}\right) d \theta-c_{l} \cdot\left(\frac{p_{h}-p_{l}}{v_{h}-v_{l}}-\frac{p_{l}}{v_{l}}\right)+\int_{\frac{p_{h}-p_{l}}{v_{h}-v_{l}}}^{1}\left(\theta \cdot v_{h}\right) d \theta \\
& -c_{h} \cdot\left(1-\frac{p_{h}-p_{l}}{v_{h}-v_{l}}\right)
\end{aligned}
$$

yielding 


$$
\begin{aligned}
& S W\left(p_{l}, p_{h}\right) \\
& \quad=\frac{v_{l} v_{h}\left(v_{h}-v_{l}\right)+2 c_{l}\left(p_{l} v_{h}-p_{h} v_{l}\right)-v_{l} p_{h}\left(p_{h}-2 p_{l}\right)-p_{l}^{2} v_{h}-2 v_{l} c_{h}\left(p_{l}-p_{h}+v_{h}-v_{l}\right)}{2\left(v_{h}-v_{l}\right) v_{l}} .
\end{aligned}
$$

Next, note that the Hessian is negative definite:

$$
\begin{aligned}
& \frac{d^{2} S W\left(p_{l}, p_{h}\right)}{d p_{h}^{2}}=-\frac{1}{\left(v_{h}-v_{l}\right)}<0, \\
& \frac{d^{2} S W\left(p_{l}, p_{h}\right)}{d p_{l}^{2}}=-\frac{v_{h}}{v_{l}\left(v_{h}-v_{l}\right)}<0, \\
& \frac{d^{2} S W\left(p_{l}, p_{h}\right)}{d p_{l} d p_{h}}=0
\end{aligned}
$$

Hence,

$$
\operatorname{det}\left[\begin{array}{ll}
-\frac{1}{\left(v_{h}-v_{l}\right)} & 0 \\
0 & -\frac{v_{h}}{\left(v_{l}-v_{h}\right) v_{l}}
\end{array}\right]>0
$$

The social optimum is thus given by the first-order conditions.

$$
\begin{aligned}
& \frac{d S W\left(p_{l}, p_{h}\right)}{d p_{h}}=0 \Rightarrow p_{h}=c_{h}+p_{l}-c_{l}, \\
& \frac{d S W\left(p_{l}, p_{h}\right)}{d p_{h}}=0 \Rightarrow p_{l}=c_{l}+\frac{p_{h} v_{l}-c_{h} v_{l}}{v_{h}} .
\end{aligned}
$$

Combining gives

$$
p_{l}=c_{l} \text { and } p_{h}=c_{h}
$$

Proof of Proposition 6. Let us first consider the case where $\delta \geq \widehat{\delta} \equiv \max \left\{\delta_{l}^{* *}, \delta_{h}^{* *}\right\}$ so that the industry-wide cartel will set the unconstrained monopoly prices as specified in Proposition 2. Combining the collusive prices as given in Propositions 1 and 2 with the general social welfare function gives

$$
\begin{aligned}
S W^{l} & =\frac{8 c v_{h} v_{l}+4 v_{h}^{2}\left(v_{h}-v_{l}\right)-4 c v_{h}\left(2 v_{h}-c\right)-c^{2} v_{l}}{8 v_{h}\left(v_{h}-v_{l}\right)}, \\
S W^{h} & =\frac{3 c\left(c+2 v_{l}\right)-6 c v_{h}-v_{l}^{2}+v_{h}\left(3 v_{h}-2 v_{l}\right)}{8\left(v_{h}-v_{l}\right)}, \\
S W^{l h} & =\frac{2 v_{h}\left(6 v_{h}^{3}+v_{l}^{3}\right)-2 v_{h} c\left(12 v_{h}^{2}+5 v_{l}^{2}\right)+2 c^{2} v_{l}^{2}-v_{l} v_{h}^{2}\left(13 v_{h}+v_{l}\right)+v_{l} v_{h} c\left(34 v_{h}-9 c\right)+12 c^{2} v_{h}^{2}}{2\left(v_{h}-v_{l}\right)\left(4 v_{h}-v_{l}\right)^{2}}, \\
S W^{a} & =\frac{3\left(v_{h}-v_{l}\right)\left(v_{h}-2 c\right)+3 c^{2}}{8\left(v_{h}-v_{l}\right)} .
\end{aligned}
$$

Comparing the societal surplus under a single segment-wide cartel regime with the social welfare with an industry-wide cartel yields 


$$
\begin{aligned}
S W^{l}-S W^{a} & =\frac{\left(v_{h}-c\right)^{2}}{8 v_{h}}>0, \\
S W^{h}-S W^{a} & =\frac{1}{8} v_{l}>0 .
\end{aligned}
$$

Next, let us compare social welfare under the two partial cartels scenario with social welfare under unconstrained full collusion:

$$
S W^{l h}-S W^{a}=v_{l} \cdot \frac{\left(v_{h}-v_{l}\right)\left(v_{h}\left(20 v_{h}-11 v_{l}\right)-2 c\left(4 v_{h}-3 v_{l}\right)\right)-\left(12 v_{h}-5 v_{l}\right) c^{2}}{8\left(v_{h}-v_{l}\right)\left(4 v_{h}-v_{l}\right)^{2}}
$$

Notice that $S W^{l h}-S W^{a}>0$ for $c \rightarrow 0$ and that the difference $S W^{l h}-S W^{a}$ decreases monotonically in $c$. Substituting the upper bound $c=v_{h}-v_{l}$ (Assumption 1) in $S W^{l h}-S W^{a}$ gives

$$
\frac{v_{l}^{2}\left(20 v_{h}-11 v_{l}\right)}{8\left(4 v_{h}-v_{l}\right)^{2}}>0
$$

We conclude that social welfare under partial collusion is strictly higher than under an industry-wide cartel capable of sustaining the joint profit maximum.

Finally, let us consider the case where $\delta \in[\widetilde{\delta}, \widehat{\delta})$ so that the industry-wide cartel sets prices below the monopoly level. We show that social welfare declines when the incentive constraints are binding and the prices set by the firms continuously increase along the interval ranging from the two partial cartels to the industry-wide cartel prices as specified in Proposition 2.

Now suppose that both incentive constraints are binding (Lemma 1) and consider a marginal increase in the discount factor. The binding incentive constraints are given by

$$
\begin{array}{r}
\left(p_{h}-c_{h}\right) \cdot\left(v_{h}-v_{l}-p_{h}+p_{l}\right)-(1-\delta) \cdot h \cdot \frac{\left(v_{h}-v_{l}+p_{l}-c\right)^{2}}{4}=0 \\
p_{l} \cdot\left(v_{l} p_{h}-v_{h} p_{l}\right)-(1-\delta) \cdot l \cdot \frac{\left(v_{l} p_{h}\right)^{2}}{4 v_{h}}=0 .
\end{array}
$$

Since a marginal increase in the discount factor relaxes both incentive constraints this yields an increase in collusive prices. Specifically, we can distinguish a direct effect and an indirect effect. The latter comes from the fact that a price increase in one segment enables a price increase in the adjacent segment. Using the binding incentive constraints and solving for $p_{h}$ and $p_{l}$ yields

$$
\begin{gathered}
p_{h}\left(p_{l}\right)=\frac{1}{2}\left(c+v_{h}-v_{l}+p_{l}\right)+\frac{1}{2} \sqrt{(h(\delta-1)+1)\left(v_{h}-v_{l}-c+p_{l}\right)^{2}}, \\
p_{l}\left(p_{h}\right)=\frac{1}{4 v_{h}^{2}}\left[2 p_{h} v_{h} v_{l}+2 \sqrt{p_{h}^{2} v_{h}^{2} v_{l}^{2}(l(\delta-1)+1)}\right]
\end{gathered}
$$

These expressions show that the two prices $p_{h}$ and $p_{l}$ are positively related. Starting with an increase in $p_{h}$, the impact on social welfare is 


$$
\begin{aligned}
\frac{d S W}{d p_{h}}= & -\frac{d p_{l}\left(p_{h}\right)}{d p_{h}} v_{l}-\frac{1-\frac{d p_{l}}{d p_{h}}}{v_{h}-v_{l}} \cdot\left(v_{h}-v_{l}-c\right)=-\frac{d p_{l}\left(p_{h}\right)}{d p_{h}} v_{l} \\
& -\left(1-\frac{d p_{l}\left(p_{h}\right)}{d p_{h}}\right) \cdot D_{h}^{*} \cdot h .
\end{aligned}
$$

The first term captures the market size effect. Since an increase in $p_{h}$ has a positive indirect effect on $p_{l}$ this effect is negative. The second term captures the market share effect. If $p_{h}$ increases, then some customers move to the standard segment. This effect is, however, countered by the indirect positive effect on $p_{l}$. Nevertheless, a sufficient condition for the market share effect to be negative is that $\frac{d p_{l}\left(p_{h}\right)}{d p_{h}}<1$, which holds because $0<(l(\delta-1)+1)<1$ and

$$
\frac{d p_{l}}{d p_{h}}=\frac{v_{l}}{2 v_{h}}\left(\frac{(l(\delta-1)+1) p_{h} v_{h} v_{l}}{\sqrt{(l(\delta-1)+1) p_{h}^{2} v_{h}^{2} v_{l}^{2}}}+1\right)<1
$$

Let us now turn to the increase of $p_{l}$. The impact on social welfare is given by

$$
\frac{d S W}{d p_{l}}=\frac{1}{v_{l}} \cdot\left(-v_{l}\right)+\frac{\frac{d p_{h}}{d p_{l}}-1}{v_{h}-v_{l}} \cdot\left(v_{h}-v_{l}-c\right)=-1-\left(1-\frac{d p_{h}}{d p_{l}}\right) \cdot D_{h}^{*} \cdot h<0 .
$$

As before, the first term captures the market size effect and the second term captures the market share effect. Since $\frac{d p_{h}}{d p_{l}} \geq 0$ and $D_{h}^{*} \cdot h<1$, the combined effect is negative. Taken together, societal surplus therefore gradually decreases when prices increase marginally along the interval as specified in Proposition 2. We conclude that $S W^{l h} \geq S W^{a}$.

Proof of Proposition 7. Social welfare under the different partial cartel scenarios is provided in the proof of Proposition 6. Comparing them yields the following thresholds in reference to $k=c /\left(v_{h}-v_{l}\right)$ :

$$
\begin{aligned}
& S W^{h} \lesseqgtr S W^{l h} \Leftrightarrow c /\left(v_{h}-v_{l}\right) \lesseqgtr k_{1} \equiv\left(4 v_{h}+v_{l}\right) /\left(12 v_{h}-5 v_{l}\right) \in(0,1), \\
& S W^{h} \lesseqgtr S W^{l} \Leftrightarrow c /\left(v_{h}-v_{l}\right) \lesseqgtr k_{2} \equiv\left(v_{h}-\sqrt{v_{h} v_{l}}\right) /\left(v_{h}-v_{l}\right) \in(0,1), \\
& S W^{l h} \lesseqgtr S W^{l} \Leftrightarrow c /\left(v_{h}-v_{l}\right) \lesseqgtr k_{3} \equiv\left[2\left(4 v_{h}-3 v_{l}\right) v_{h}\right] /\left(8 v_{h}^{2}-2 v_{h} v_{l}+v_{l}^{2}\right) \in(0,1) .
\end{aligned}
$$

It can be readily verified that there is a quality ratio:

$$
v_{h} / v_{l}=\rho \equiv \sqrt{2} / 2+3 / 4
$$

for which all thresholds are equal, that is, $k_{1}=k_{2}=k_{3}$. Moreover, if $v_{h} / v_{l}>\rho$, then $k_{1}>k_{2}>k_{3}$ and if $v_{h} / v_{l}<\rho$, then $k_{3}>k_{2}>k_{1}$. The welfare ranking under the different partial cartel regimes as specified in the proposition then follows accordingly. 


\section{APPENDIX B: MULTIPRODUCT FIRMS}

The analyses in this paper have been performed under the assumption that each producer offers a single quality. Alternatively, sellers may simultaneously supply multiple quality variants. In this appendix, we briefly discuss how allowing for such multiproduct firms might affect our main findings. To be clear, a multiproduct firm within our framework is a firm with two divisions; one in each segment. All other assumptions are as above.

To begin, it can be easily verified that the presence of multiproduct firms does not alter the impact of the all-inclusive cartel. The reason is that in our setting the industry-wide cartel de facto operates as a multiplant monopolist, which implies that all pricing externalities are internalized. Therefore, and irrespective of the number of multiproduct members, prices are as given by Proposition 2. In light of the main analysis above, these prices are also sustainable since the incentive constraint of a multiproduct firm is effectively a combination of incentive constraints of two independently operating quality divisions.

Next, consider the case of two segment-wide partial cartels. How would the presence of multiproduct firms affect the collusive outcome as specified in Proposition 1? To address this question, let the number of multiproduct firms be given by $k \geq 0$. The collusive best-replies of the standard and premium segment-wide cartels are then, respectively, given by

$$
p_{l}^{l h}=\frac{v_{l}\left(1+\frac{k}{h}\right) p_{h}^{l h}+v_{h} c_{l}-\frac{k}{h} v_{l} c_{h}}{2 v_{h}}
$$

and

$$
p_{h}^{l h}=\frac{\left(v_{h}-v_{l}\right)+\left(1+\frac{k}{h}\right) p_{l}^{l h}+c_{h}-\frac{k}{l} c_{l}}{2} .
$$

Note that when there are no multiproduct firms $(k=0)$, the collusive outcome is the same as in Proposition 1. By contrast, if all firms would sell both quality variants $(k=l=h)$, then the joint profit maximum coincides with that of an industry-wide cartel (Proposition 2). In general, the more multiproduct firms in this case, the larger the extent to which pricing externalities are internalized and the higher are the profit-maximizing prices.

This solution is feasible whenever some collusion is sustainable. The reason is as follows. Since the collusive segment price is weakly below the best-response to the collusive price in the other segment, the optimal deviating strategy is to undercut the collusive price(s) by the smallest possible amount. This implies that incentive compatibility is effectively only determined by the discount factor and the number of firms involved. In fact, the incentive constraint of a multiproduct firm is less tight than that of a single-product seller in this case since deviating in one submarket induces a lower cartel price in the adjacent segment.

Finally, let us discuss the possibility of a single segment-wide partial cartel with one or more multiproduct members. In this situation, the collusive best-reply functions are the same as above. The key difference with the two segment-wide partial cartels case is, however, that the price in the noncollusive segment equals marginal costs when the number of outsiders exceeds two. Therefore, independent of the number of multiproduct firms, prices remain as in Proposition 1. 
Yet, this situation changes when there are only two firms active in the adjacent segment. To see this, suppose there is a single partial cartel in the premium submarket. Suppose further that $k=1$ and $l=2$. The multiproduct firm could now contemplate the following strategy. Rather than keeping price at costs in the standard segment it may increase this price. This implies that the multiproduct firm sacrifices all its market share in the low-quality submarket, because the best-reply by the outsider is to price below it. Such a strategy is nevertheless profitable since profits remain zero in the low-quality submarket and increase in the premium segment. The latter is due to the strategic complementarity of the choice variable.

To see that this strategy is also feasible, consider the incentive constraint of the multiproduct firm when it would indeed set price above costs in the standard segment:

$$
\begin{aligned}
& \frac{1}{1-\delta} \cdot\left(p_{h}^{c}-c_{h}\right) \cdot \frac{v_{h}-v_{l}-p_{h}^{c}+p_{l}}{\left(v_{h}-v_{l}\right) h} \geq\left(p_{h}^{d}-c_{h}\right) \cdot \frac{v_{h}-v_{l}-p_{h}^{d}+p_{l}}{\left(v_{h}-v_{l}\right)} \\
& \quad+\left(p_{l}^{d}-c_{l}\right) \cdot \frac{v_{l} p_{h}^{c}-v_{h} p_{l}}{\left(v_{h}-v_{l}\right) v_{l}}
\end{aligned}
$$

First note that in this case the multiproduct firm faces a tighter incentive constraint than singleproduct firms because its deviating profits are (weakly) higher, whereas collusive profits are the same. Second, since price exceeds costs in the standard segment, the optimal deviating strategy for the multiproduct firm is to cut price in both submarkets simultaneously. Finally, the outsider charges a price weakly below the best-response to the collusive premium price and that collusive price itself is weakly below the best-response to the price in the low-quality segment. Optimal deviating prices are therefore (approximately) equal to the segment prices, that is, $p_{h}^{d}=p_{h}^{c}$ and $p_{l}^{d}=p_{l}$. This reduces the incentive constraint of the multiproduct firm to

$$
[1-(1-\delta) h] \cdot\left(p_{h}^{c}-c_{h}\right)\left(v_{h}-v_{l}-p_{h}^{c}+p_{l}\right)-(1-\delta) h \cdot\left(p_{l}-c_{l}\right) \frac{v_{l} p_{h}^{c}-v_{h} p_{l}}{v_{l}} \geq 0
$$

Provided that some collusion is sustainable, the collusive price $p_{h}^{c}$ is the same as in Proposition 1 when $p_{l}=c_{l}$. However, the above strategy is also feasible for a high enough discount factor. In fact, if $\delta \rightarrow 1$, then the multiproduct firm could set and sustain the best-responses: $p_{l}=\left(v_{l} p_{h}^{c}+v_{h} c_{l}\right) / 2 v_{h}$ and $p_{h}^{c}=\left(v_{h}-v_{l}+p_{l}+c_{h}\right) / 2$. Notice that these are precisely the prices that would result in case of two segment-wide partial cartels. In a similar vein, multiproduct firms may lead to higher collusive prices when there is a single segment-wide cartel in the standard segment and there are two firms active in the adjacent premium segment.

In sum, in most cases the presence of multiproduct firms does not affect the collusive outcome, but when it does, cartel prices are higher. This can occur when there are two partial cartels or when there is a single partial cartel and there are two firms active in the adjacent segment. 